\title{
Abnormal fucosylation of-ileal mucus in cystic fibrosis: II A histochemical study using monoclonal antibodies to fucosyl oligosaccharides
}

\author{
A King, M McLeish, S Thiru
}

\begin{abstract}
Abnormal fucosylation of cystic fibrosis mucin was previously shown using peroxidase conjugated lectins on ileal tissue sections. These abnormally fucosylated glycoproteins were investigated further using monoclonal antibodies to fucosyl oligosaccharides based on type 1 and type 2 blood group precursor chains. The results of this study, using monoclonal antibodies to blood group glycoproteins in cystic fibrosis, were negative, yet abnormal fucosylation had been found using lectin histochemistry. Using monoclonal antibodies, lectins, and appropriate enzymes, such as glycosyl hydrolases, it should be possible to delineate further the abnormality found in glycoproteins in cystic fibrosis on appropriately fixed ileal sections, obtained from infants at term presenting with meconium ileus.
\end{abstract}

The increased viscosity of the mucus in cystic fibrosis is still unexplained, despite much speculation..$^{1-5}$ We have shown that there is a histochemical abnormality in the ileal mucus in cystic fibrosis, using peroxidase conjugated lectins. ${ }^{6}$ Strong staining of ileal goblet cells by the fucose binding lectin Lotus tetragonolobus (LTG) persisted until term; in normal controls the reaction began to diminish at about 36 weeks of gestation, and was totally absent at term and thereafter. This observation confirmed previous biochemical studies which have shown increased fucosylation of both mucus and membrane glycoproteins in cystic fibrosis. ${ }^{7-9}$

When another fucose binding lectin Ulex europaeus (UEA) was used in the same study, however, there was no demonstrable difference between cases of cystic fibrosis and controls. This may perhaps be explained by the fact that UEA and LTG differ slightly in their binding sites..$^{10}$ Although lectins may be considered identical in terms of monosaccharide specificity, they can also discriminate between fine differences in more complex structures. For instance, LTG is specific for fucosyl oligosaccharides based on the type 2 blood group precursor chains, but unlike UEA, fails to react with oligosaccharides of the type 1 chain. Furthermore, LTG is more specific for difucosylated rather than monofucosylated type 2 chains. ${ }^{112}$ More precise identification of carbohydrate structures using lectin reactions is not, however, possible.
Monoclonal antibodies offer an advantage over lectins in this respect, and several directed against the fucosyl oligosaccharides based on both type 1 and type 2 chains are now available. They have already been applied successfully in fixed tissues using an immunoperoxidase method ${ }^{13}$ to analyse both the structure and localisation of carbohydrate antigens. ${ }^{14}$ We therefore used a panel of monoclonal antibodies directed against carbohydrate differentiation antigen ${ }^{15}$ to investigate further the abnormal properties of mucus in cystic fibrosis.

\section{Methods}

Formalin fixed, paraffin wax embedded specimens of small intestine from necropsies and surgery were used. We studied the same cases used in our previous report ${ }^{6}$ comprising 24 cases of cystic fibrosis and 48 control subjects. The ages of the cases ranged from 17 weeks' gestation to 3 months post partum. The blood group and secretor state were not known.

Five monoclonal antibodies were used (table). An indirect immunoperoxidase method was used. The monoclonal antibodies were diluted with $0.5 \mathrm{M}$ TRIS buffered saline (TBS), $\mathrm{pH} 7 \cdot 6$, with the addition of $0.1 \%$ bovine serum albumin, and initially the antibodies were tested on several fetal tissues to assess the optimal dilution. Sections $(4-5 \mathrm{~mm})$ were cut from the formalin fixed, paraffin wax embedded specimens, mounted on glass slides, and dried at $37^{\circ} \mathrm{C}$ overnight. Sections were dewaxed in xylene and taken through graded alcohols to water. Endogenous peroxidase was blocked by treating the sections with a 3\% aqueous solution of hydrogen peroxide for 15 minutes. After rinsing in tap water the sections were warmed to $37^{\circ} \mathrm{C}$ in a water bath and then placed in a freshly prepared solution of $0.1 \%$ trypsin (Sigma Chemicals) containing $0.01 \mathrm{M}$ calcium chloride, $\mathrm{pH} 7.8$, at $37^{\circ} \mathrm{C}$ for 20 minutes. They were then rinsed in cold running tap water to stop trypsin activity before being placed in a bath of TBS. The slides were removed from the bath, excess TBS wiped off, and the monoclonal antibodies applied to the sections which were incubated in a moist atmosphere for 45-60 minutes. The monoclonal antibodies were washed off with TBS and then washed in fresh TBS for 10 minutes. Peroxidase conjugated rabbit-anti mouse immunoglobulins (Dako) diluted 1 in 100 with TBS were then applied for 30 minutes and then washed off as before. The horseradish peroxidase was visualised using $3 \cdot 3$ diaminoben- 
Monoclonal antibodies against fucosyl oligosaccharides

\begin{tabular}{|c|c|c|c|c|c|}
\hline \multicolumn{2}{|c|}{ Structure } & Specificity & Source & Name & Reference \\
\hline \multicolumn{6}{|c|}{ Type 1 chain } \\
\hline (1) & $\begin{array}{c}\text { Gal } \beta 1 \rightarrow 3 \mathrm{GlcNAc} \beta 1 \rightarrow 3 \mathrm{Gal}- \\
\uparrow 4 \\
\text { Fuc } \alpha 1\end{array}$ & $\mathrm{Le}^{\mathrm{a}}$ & $\begin{array}{l}\text { Chembiomed, } \\
\text { Alberta, } \\
\text { Canada }\end{array}$ & AH8-34 & 16 \\
\hline (2) & 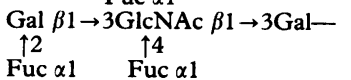 & $\mathrm{Le}^{\mathrm{b}}$ & $\begin{array}{l}\text { Chembiomed, } \\
\text { Alberta, } \\
\text { Canada }\end{array}$ & AY3-178 & 16 \\
\hline (3) & 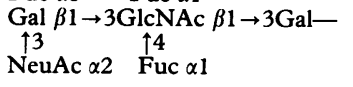 & Sialyl Le $\mathrm{a}^{\mathrm{a}}$ & $\begin{array}{l}\text { CIS, } \\
\text { High Wycombe }\end{array}$ & $19 \cdot 9$ & 17 \\
\hline \multicolumn{6}{|c|}{ Type 2 chain } \\
\hline (4) & $\underset{\substack{\text { Gal } \beta 1 \rightarrow 4 \\
\text { Fuc } 1}}{\text { GlcNAc } \beta 1 \rightarrow 3 \mathrm{Gal}-}$ & $X\left(L e^{x}\right)$ & $\begin{array}{l}\text { Becton } \\
\text { Dickinson }\end{array}$ & LeuM1 & 18 \\
\hline (5) & $\begin{array}{l}\text { Gal } \beta 1 \rightarrow 4 \text { GlcNAc } 1 \rightarrow 3 \mathrm{Gal}- \\
\uparrow 2 \\
\text { Fuc } \alpha 1 \quad \text { Fuc } \alpha 1\end{array}$ & $\mathrm{Y}\left(\mathrm{Le}^{\mathrm{y}}\right)$ & $\begin{array}{l}\text { Professor } \\
\text { Baldwin }\end{array}$ & $\mathrm{C} 14$ & 19 \\
\hline
\end{tabular}

idine hydrochloride (DAB). The sections were counterstained with a weak haematoxylin, dehydrated, cleared and mounted in DPX.

\section{Results}

The sections were analysed for the intensity and distribution of staining as reported previously. ${ }^{6}$ The intensity was graded as $1+$ for minimal staining and $3+$ for strong staining. Depending on the monoclonal antibody used, positive staining was present in goblet cell mucin, absorptive epithelial cells, basal cells in the crypts and the brush border.

There was no difference in staining between mucins in cystic fibrosis and in controls with any of the antibodies used at any gestational age. With each monoclonal antibody, however, there was great variation in the pattern of staining between cases which was possibly due to differences in gestational age and secretor state, which was not known for any of the cases studied. Both Lewis $a / b$ and Lewis $x / y$ are changed in secretions under the influence of the

Figure 1 Ileum at 26 weeks' gestation showing positive staining of goblet cells with monoclonal antibody 19.9.

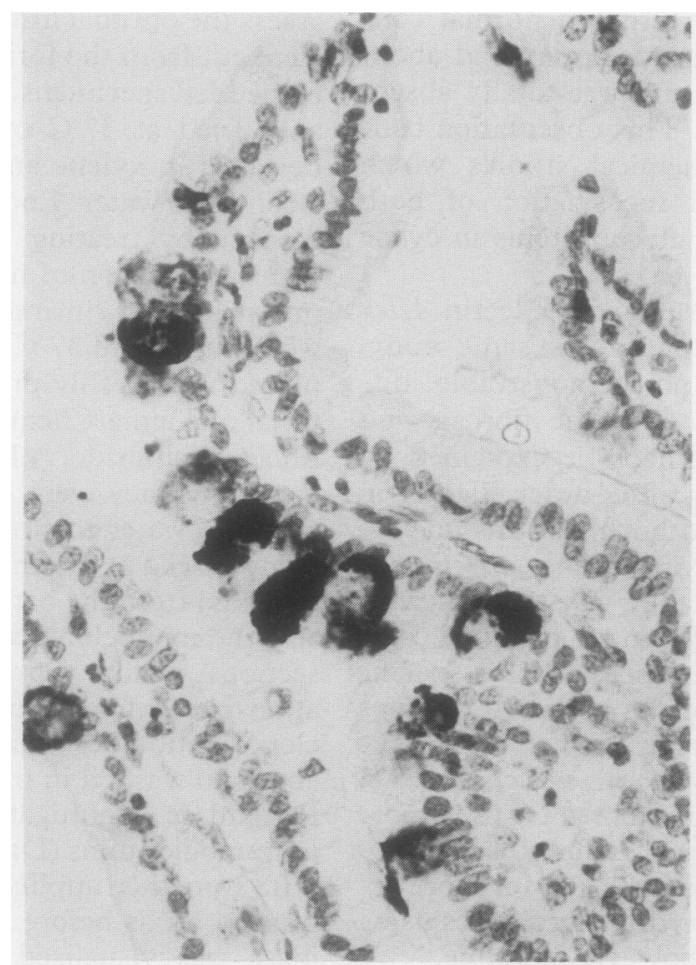

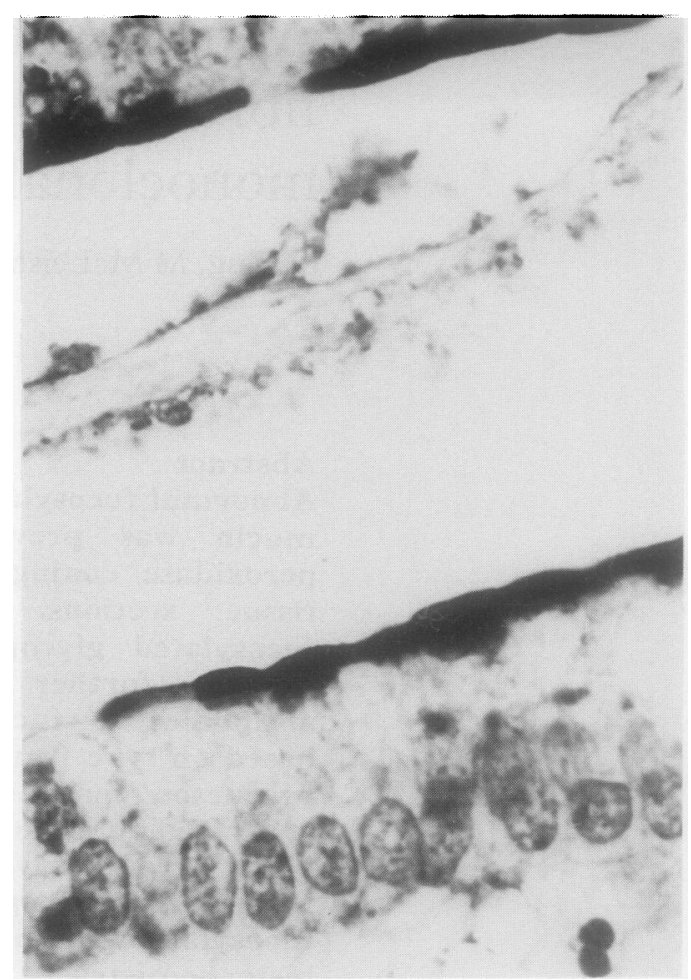

Figure 2 Ileum at 38 weeks' gestation. There is strong staining of the brush border with Leu M1.

secretor gene. The variation in staining might also have been due to the different fixation times used for surgical and necropsy specimens and variable fixation procedures among hospitals.

Lewis $^{a}$ All cells in the ileal mucosa stained (absorptive, goblet, and basal cells). The brush border stained more intensely with an increase in gestational age.

Lewis $^{b}$ Goblet cells were stained with this monoclonal antibody in some cases, but were negative in others. Goblet cell staining was not correlated with gestational age.

Sialyl $L e^{a}$ Before 34 weeks' gestation there was strong staining of ileal goblet cells (fig 1) in cases of cystic fibrosis and controls, but the intensity declined subsequently, and by three months post partum there was no staining of ileal cells in any of the cases. In a few cases sections of pancreas were also stained with this monoclonal antibody. There was strong staining of the pancreatic duct epithelial cells and this was particularly intense in cases of cystic fibrosis, but only after secondary changes of fibrosis and acinar dilatation hau developed in the pancreas.

Lewis $x \quad$ The brush border stained strongly in most cases and this became more intense with increasing gestational age (fig 2).

Lewis $y$ The basal cells at the base of the crypts stained in all cases. The goblet cells and absorptive cells in the tips of the villi in some cases also stained, but this was not related to cases of cystic fibrosis (fig 3 ). 
Figure 3 Ileum at 40 weeks' gestation. The cells at the base of the crypts and occasional goblet cells stain with C14.

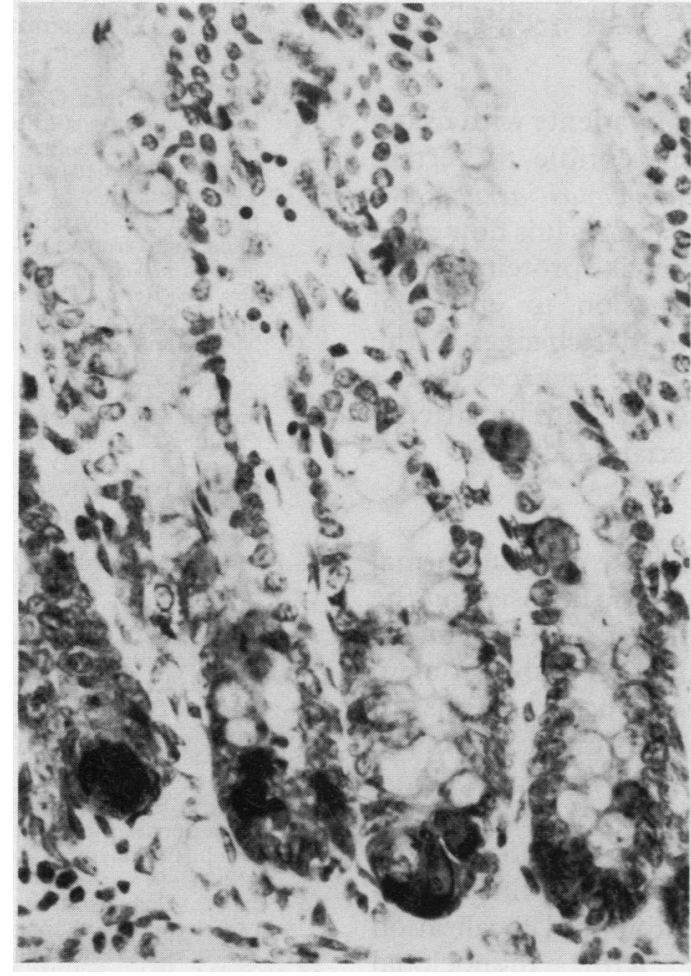

Discussion

Mucus is rich in high molecular weight glycoproteins, synthesised and secreted by the goblet cells in the gastrointestinal tract and the mucous cells of submucosal glands. The carbohydrate structures of mucins are interesting in that identical structures also occur on glycoproteins and glycolipids which are all an integral part of the cell membrane. These mucin glycoproteins belong to a family of carbohydrate structures which includes the major blood group antigens whose expression changes during differentiation and oncogenesis. ${ }^{1520}$ The carbohydrate chains are built of backbone regions consisting of alternating galactose and $\mathrm{N}$-acetyl galactosamine residues which may be joined by two different types of linkage, resulting in type 1 and type 2 precursor chains. Further sequential addition of saccharides such as fucose, galactose, and $\mathrm{N}$-acetyl galactosamine results in peripheral regions of varying specificities.

Many monoclonal antibodies directed against these carbohydrate antigens are now available and several studies have shown that they can be used on paraffin wax sections. ${ }^{1314} 17$ Using five monoclonal antibodies directed against fucosylated oligosaccharides we hoped to elucidate further the abnormal fucosylation shown by our lectin histochemical study. ${ }^{6}$ No differences between cases of cystic fibrosis and age matched controls were found, however, in the staining of ileal goblet cells, although there was a change of expression of several antigens throughout gestation.

Our previous study indicated that LTG (which binds most strongly to difucosylated type 2 chains) continued to stain ileal mucus in cases of cystic fibrosis after 36 weeks in contrast to normal controls. Therefore, it might have been predicted that the $\mathrm{Y}$ hapten $\left(\mathrm{Le}^{\mathrm{y}}\right)$ which has the structure:

$$
\begin{array}{cc}
- \text { Gal } \beta 1->4 \mathrm{GlcNAc} \beta 1->3 \mathrm{Gal} \\
\uparrow 2 & \uparrow 3 \\
\text { Fuc } \alpha 1 & \text { Fuc } \alpha 1
\end{array}
$$

would be abnormally expressed in cystic fibrosis. This possibility was investigated using monoclonal antibody C14, which is directed against this epitope, but in fact no abnormal staining was demonstrable in cystic fibrosis. Expression of $\mathrm{Le}^{\mathrm{y}}$ is also controlled by secretor state, however, and as cystic fibrosis is not related to the latter such a result is perhaps not surprising. ${ }^{21}$ It has been suggested that blood group substances may be changed in cystic fibrosis, ${ }^{22}$ but this has yet to be proved. A prospective study using material fixed under controlled conditions with knowledge of the secretory state and blood group would be more informative.

LTG binds to other glycoproteins such as serum glycoproteins, and small amounts of these are present in mucus and are integrated into the cell membrane. Scanlin found increased fucosylation of membrane oligosaccharides in cystic fibrosis and has proposed a structure for the carbohydrate containing changed fucose. ${ }^{9}$ This is a biantennary $\mathrm{N}$-linked glycopeptide in which the epitope recognised by $\mathrm{C} 14$ ( $\mathrm{Y}$ hapten) is present. The $\mathrm{Y}$ hapten could be masked by sialic acid residues several of which were also present in this proposed structure.

Any abnormality in a carbohydrate chain which is secreted in mucus and is also carried on both glycoprotein and glycolipids of the cell membrane would explain several important facts about cystic fibrosis.

The factors affecting viscosity of mucus are still poorly understood but a change in carbohydrate composition may facilitate gel formation. ${ }^{23}$ For example, earlier studies have shown that high molecular weight glycoconjugates secreted by cystic fibrosis respiratory epithelium in situ are oversulphated. ${ }^{24}$ It was not clear, however, if this was an acquired abnormality or an inherent defect in cystic fibrosis. Recently Frates et al have shown that cultured cystic fibrosis upper respiratory epithelia from adults produce mucus glycoproteins at increased rates and a higher level of sulphation and acidity compared with that of controls. ${ }^{25}$ Cheng et al have shown similar increases in sulphation of mucin glycoprotein fraction from nasal epithelial cells in healthy full term infants and infants with confirmed cystic fibrosis. ${ }^{26}$ Ryley et al showed an increase in the fucose content of meconium in cases of cystic fibrosis. ${ }^{27}$

The finding of deficient ion transport and changed chloride permeability in cystic fibro$\mathrm{sis}^{28}$ suggest a possible defect in band 3 protein. A recent immunohistological study using a monoclonal antibody against the peptide (43K) component of band 3 , however, showed no difference between patients with cystic fibrosis and controls. ${ }^{29}$ Carbohydrate differentiation antigens occur on band 3 of the erythrocyte membrane, ${ }^{30}$ so possibly it is the change in the 
carbohydrate component which affects ion transport.

It has long been noted that patients with cystic fibrosis are peculiarly susceptible to certain infections such as Pseudomonas aeruginosa, especially the mucoid variant. As it is now clear that bacteria produce lectin-like proteins which may be involved in adhesion to epithelial cells, ${ }^{31}$ it is quite possible that changes in the carbohydrate moieties at the surfaces of the cells in cystic fibrosis could account for susceptibility to particular bacterial infections.

There is growing evidence that abnormal fucosylation is present in cystic fibrosis, but the exact structure of the oligosaccharide remains to be determined. Investigation of the problem by extraction and biochemical analysis of mucus is both difficult and time consuming, but we have been able to show that monoclonal antibodies directed against carbohydrate antigens can be used on fixed sections of the ileum in cystic fibrosis. Both the fine carbohydrate structure and histological localisation can be determined with monoclonal antibodies. ${ }^{14}$ In addition, by investigating the ileum at term we have also avoided the secondary problems of infection and treatment. The latter make interpretation of biochemical analysis of respiratory tract mucins difficult and may explain conflicting results. ${ }^{32}$ Further analysis of cell surface carbohydrates in fixed sections is possible using glycosyl hydrolases and thus determining if the carbohydrate chains are linear, branched, biantennary or contain mannose. Therefore, it seems likely that using a combination of monoclonal antibodies and appropriate enzymes a better understanding will emerge of the changed fucosylation we have shown in glycoproteins in patients with cystic fibrosis.

Since this work was completed the cystic fibrosis gene has been identified..$^{33}$ The predicted cystic fibrosis gene product seems to be a membrane associated protein involved in the regulation of ion transport and also possibly the regulation of protein-glycoprotein secretory functions of epithelial cells.

We are grateful to Dr J Keeling, Edinburgh, who offered much encouragement and advice throughout this project. We are also indebted to Dr D Scott, Newcastle, Dr A Allibone, Leeds, and Dr J Berry, Bristol, who provided us with blocks from cystic fibrosis cases. We are grateful to Chris Burton for help with the photography and Susen Green for secretarial assistance.

1 Wesley A, Forstner J, Qureshi R, Mantle M, Forstner G. Hum 1983;17:65-9.

2 Mantle M, Forstner G, Forstner J. Biochemical characterisation of the component parts of intestinal mucin from patients with cystic fibrosis. Biochem J 1984;224:345-54.
Chace KV, Flux M, Sachdev GP. Comparison of physicochemical properties of purified mucus glycoproteins isolated from respiratory sections of cystic fibrosis and asthmatic patients. Biochemistry 1985;24:7334-41.

4 Alhadeff JA. Glycoproteins and cystic fibrosis: a review. Clin Genet 1978;14:189-201.
5 Forstner J, Wesley A, Mantle M, Kopelman J, Man D, Forstner G. Abnormal mucus: nominated but not ye elected. J Pediatr Gastroenterol Nutr 1984;3(Supp 1):S67-S73.

6 Thiru S, Devereux G, King A. Abnormal fucosylation of ileal mucins in cystic fibrosis: A histochemical study using monoclonal antibodies to fucosyl oligosaccharides. J Clin Pathol 1990;43:1014-8.

7 Clamp JR, Gough M. Study of the oligosaccharide units from mucus glycoproteins of meconium from normal infants and from cases of cystic fibrosis with meconium infants and from cases of cystic

8 Ryley HC, Rennie D, Bradley DM. The composition of a mucus glycoprotein from meconium of cystic fibrosis, healthy pre-term and full-term neonates. Clin Chim Acta 1983;135:49-56.

9 Scanlin TF, Wang Y, Glick MC. Altered fucosylation of membrane glycoproteins from cystic fibrosis fibroblasts. Pediatr Res 1985;19:368-74.

10 Debray H, Decout D, Strecker G, Spik G, Montreuil J. Specificity of twelve lectins towards oligosaccharides and glycopeptides related to $\mathrm{N}$-glycosyl proteins. Eur J Biochem 1981;117:41-55.

11 Pereira MEA, Kabat EA. Specificity of purified haemagglutinin (lectin) from Lotus tetragonolobus. Biochemistry 1974;13:3184-92.

12 Pereira MEA, Kisailus EC, Grenzof F, Kabat EA. Immunochemical studies on the combining site of the blood group chemical studies on the combining site of the blood group H-specific lectin from Ulex eu
Biochem Biophys 1978;185:108-15.

13 Ernst C, Atkinson B, Wysocka $M$, et al. Monoclona antibody localisation of Lewis antigens in fixed tissue. $L a b$ Invest 1984;50:394-400.

14 Okada Y, Tsuji T. Immunohistochemical application of monoclonal antibodies to reveal the structure and localisation of carbohydrate antigens. J Immunol Methods 1988 ; 112:243-9.

15 Feizi T. Demonstration by monoclonal antibodies that carbohydrate structures of glycoproteins and glycolipids
are oncodevelopmental antigens. Nature 1985;314:53-7.

16 Yuan $\mathrm{M}$, Itzkowitz SH, Palekar A, et al. Distribution of blood group antigens A, B, H Lewis ${ }^{a}$ and Lewis ${ }^{b}$ in human normal, foetal and malignant colonic tissue. Cancer Res 1985;45:4499-511.

17 Atkinson BF, Ernst CS, Herlyn M, Steplewski Z, Sears HF Gastrointestinal cancer-associated antigen in immunoperoxidase assay. Cancer Res 1982;42:4820-3.

18 Huang LC, Civin CI, Magnani JL, Shaper JH, Ginsburg V. My-1, the human myeloid-specific antigen detected by mouse monoclonal antibodies, is a sugar sequence found in lacto-N-fucopentose III. Blood 1983;61:1020-3.

19 Brown A, Feizi T, Gooi HC, Embleton MJ, Picard JK, Baldwin RW. A monoclonal antibody against human colonic adenoma recognised difucosylated type-2-bloodgroup chains. Biosci Rep 1983;3:163-70.

20 Hounsell EF, Feizi T. Gastrointestinal mucins. Structures and antigenicities of their carbohydrate chains in health and disease. Med Biol 1982;60:227-36.

21 Haponik EF, Stokes D, Rosenstein BJ, Hughes WT. ABH secretor status in cystic fibrosis-a negative report. Eur Respir Dis 1985;67:381-4.

22 Rolla G, Melsen B, Sonju T. Is sulphated blood-group substance in pancreas a factor in cystic fibrosis? Acto Pathol Microbiol Scand 1978;(Sect A);86:83-6.

23 Allen A. Structure of gastrointestinal mucus glycoproteins and the viscous and gel-forming properties of mucus. $B r$ Med Bull 1978;34:28.

24 Boat TF, Cheng PW, Iyer RN, Carlson DM, Polony I Human respiratory tract secretions: mucous glycoproteins of nonpurulent tracheobronchial secretions and sputum of patients with bronchitis and cystic fibrosis. Arch Biochem Biophys 1976;177:95-104.

25 Frates RC, Kaizu T, Last JA. Mucous glycoprotein secreted by respiratory epithelial tissue from cystic fibrosis patients. Pediatr Res 1983;17:30-4.

26 Cheng PW, Boat TF Cranfil K, Yankaskas JR, Bouche RC. Increased sulfation of glycoconjugates by cultured RC. Increased sulfation of glycoconjugates by cultured nasal epithelial cells from

27 Ryley HC, Rennie D, Bradley DM. The composition of mucus glycoprotein from meconium of cystic fibrosis, healthy pre-term and full-term neonates. Clin Chim Act 1983;135:49-56.

28 Case $M$. Chloride ions and cystic fibrosis. Nature 1986 322:407.

29 Hazen-Martin DJ, Pasternack G, Hennigar RA, Spicer SS, Sens DA. Immunocytochemistry of band 3 protein in kidney and other tissues of control and cystic fibrosis patients. Pediatr Res 1987;21:235-7.

30 Childs RA, Feizi T, Fukuda M, Hakamori S. Blood-group-I activity associated with band 3 , the major intrinsic membrane protein of human erythrocytes. Biochem 1978;173:333-6.

31 Pier GB. Pulmonary disease associated with Pseudomonas aeruginosa in cystic fibrosis: current status of the host aeruginosa in cystic fibrosis: current status of the

32 Reid L. Bronchial mucus and its glycoproteins in cystic fibrosis. In: Warwick WJ, ed. 1,000 years of cystic fibrosis: fibrosis. In: Warwick WJ, ed. 1,000 years of cystic fibrosis: collected papers.

33 Riordan JR, Lap-Chee Tsui, Collins FS, et al. Identification Riordan JR, Lap-Chee Tsui, Collins FS, et al. Identificatio
of the cystic fibrosis gene. Science 1989;245:1059-79. 